\section{Johannesburg metropolitan transport and the Driessen report}

\section{Peter Penny}

Managing Director, Herbert Penny (Pty) Ltd, Property economists and brokers, P.O. Box 61127, Marshalltown 2107, South Africa

Received 10 January 1980

In September 1977 at a conference on the implementation of the Driessen Commission Report, Professor P.R. Stopher (of Northwestern University) and C.G. Wilmot presented a paper in which they warned of the 'real danger that recommendations of the Driessen Commission are being turned into firm policy, pre-empting the planning activity' and suggested that 'considerable care should be taken' in adopting the recommendations of the Commission as national policy. It appears that this warning has been largely ignored, with the consequence that one of the most far-reaching transportation planning strategies - that of the Johannesburg metropolitan area - has been based on policy as stated in the Driessen Commission Report. Although no official public action has been taken regarding the Commission's recommendations and the critics of the Commission's findings have been numerous, the report has been accepted as 'policy' by some of the most sophisticated and influential planners in South Africa.

The Driessen Commission was appointed in 1972 to look into the question of urban transportation and to formulate recommendations for improvements in the coming years. After several years of study and some delays in issuing a report, the Commission made its findings public in 1977. For the most part the Commission's investigation of urban transport trends and problems gained widespread acceptance as a valid analyis of the situation. However, many of the Commission's recommendations for remedial actions touched off an immediate and farranging debate among planners, economists, government officials and other interested parties as to the effectiveness and/or desirability of those actions. In essence, the debate signalled the fact that the Driessen recommendations were only one assessment of what should be done about urban transport, other views existed and might have validity in certain areas. 1, and many others, suggested that the Driessen Commission Report be considered as one element in formulating transportation policy but not the final word.

Stopher and Wilmot (referred to earlier) had this to say: 'The recommendations should be used as one of several possible sets of alternative strategies, and careful cost comparisons made between these and other strategies. It must be remembered that the Driessen Commission was not in a position to assess the full range of costs and consequences of its various recommendations and surely did not intend the strategies to be adopted without a careful evaluation of those strategies against alternative ones'.

Thus it is most disturbing when the planners of the country's most important metropolitan area without further consideration base the objectives of JOMET planning on the recommendations of the Driessen Commission. If JOMET planners are unchallenged in using the Driessen recommendations as the basis of their efforts, then those recommendations will become entrenched as government policy, and many far-reaching decisions will be based on assumptions not necessarily favoured by the government, and of questionable wisdom.

What's wrong with the Driessen Commission recommendations? The essence of my disagreement with the report stems from its lack of understanding of the complexity of the urban economy. The statements regarding planning made by Colin Buchanan in Durban in 1974 are instructive: 'I believe the basic reason for (city planning's) ineffectiveness can probably be traced to lack of realization of the extreme complexity of city life and city structure, and the intricate relationship between the two. Cities are unbelievably complicated organisms. It may be beyond our ability ever to understand their working in their entirety, but the more we try to understand them the less risk is there that we shall go planting our planner's boots down on all the tender human relationships and dependencies of which city life is composed. This, I think, is what we have been doing (with the best of intentions of course) with our conceptions of end state planning. The very notion of "end state" has nurtured the belief that if planning can only be sustained for long enough then eventually there will emerge a city purposedesigned for its inhabitants. But the purpose-designed city is surely a myth'.

The Driessen Commission's lack of understanding of urban economics is evidenced by its implicit endorsement of an optimum city size and its recommendations for limitations on densities, bulk and parking. Examination of some of the Commission's specific recommendations is useful.

The report recommends, inter alia, that:

'bodies and institutions at all levels associated with land use and transport planning must assign the highest priority to urban transport requirements by establishing in advance the extent of, and maximum densities and bulk factors envisaged for key business and employment areas'; and that

'planning authorities should freeze existing maximum bulk factors in the central urban area of major metropolitan areas and these maxima should be increased only after the authorities have satisfied themselves that the anticipated transport facilities will be adequate'.

I have some doubt about the purport of these words, but it seems to me that they could lead to arbitrary limitation of bulk.

In my opinion, to control bulk to conform with transport availability is to put the cart before the horse. There are underlying economic reasons why Johannesburg is larger than Kimberley which were not apparent in 1870. The planner should not attempt to restrict economic growth but should endeavour to understand it 
and to see that there is a transport system which effectively serves a city.

Large metropolitan office centres have developed because of the opportunity for pedestrian linkages in a concentrated core. From a social and economic point of view a region will function best if office activities are concentrated in a single tightly knit location. The CBD should be the largest market concentration in the metropolitan area for key business activities. It should have a limited horizontal area, and be geared to the pedestrian scale. The size of a CBD should depend on the geographic area which it serves. This may be international (such as London and New York), national (such as Johannesburg), provincial (such as Bloemfontein) or regional (such as Port Elizabeth). As the geographic area served by a CBD expands, it is the vertical rather than horizontal growth which should be emphasized. Thus planning authorities should be flexible in their attitude towards bulk and their primary concern should be to have an integrated land-usage and transport system efficiently serving the economic base and geared to the scale of that base. My principal criticism of the Driessen Report is that it seems to me to discuss traffic without relation to the function that a city performs, and to have an implied concept of an ideal size of a CBD.

A further recommendation which I find disturbing reads: 'Legislation should, where necessary, be adopted to enable local authorities to frame regulations whereby the provision of parking space in all buildings and on all sites should be controlled, and to impose a special tax or levy on parking space'. It seems to me that it would be better if local authorities were to require the provision of minimum rather than maximum parking in the $C B D-$ located at the depositing points of the freeway system, not in the prime CBD. In many cities in the United States planning ordinances require that all $C B D$ office developments include a minimum provision of parking either in the building itself or within a given distance. The particular problems of Manhattan may demand the exclusion of parking but should not be generalized to smaller cities.

The volume of cars flowing into the city should be decreased by such measures as point pricing, improved public transport systems, lanes reserved for buses, toll charges and roving taxis, but once a vehicle has gained access to the CBD it should be housed as rapidly as possible. Arbitrary limitation of parking can only decrease the operating efficiency of the CBD and create further congestion. The demand for and duration of parking should be regulated by a pricing system that is responsive to real costs.

Another area to which the Driessen Commission should have given more attention is the need for revitalization of central business districts. In the United States and England much attention has been focused on inner city problems associated with declining employment and population. Inner city problems are only now beginning to emerge in a serious form in South African cities, in particular Johannesburg. This city has spread over a vast area and in recent years that growth has begun to affect the vitality of the CBD. The withdrawal of white shoppers from the central business districts is already serious and has been exacerbated by the opening of Eastgate and several hypermarkets. For the present, the problems of retailers in the central business district are mitigated by the inflow of shoppers from Soweto, but the situation may change if efficient shopping is provided nearer to black residential areas.

Office decentralization is also increasing. Among the causes are a shortage of parking and the lack of rationale of growth in the central business district. Examination of a map of the Johannesburg CBD will reveal the pedestrian scale is being jeopardized and the financial area is being dispersed. The Carlton Centre, the Sanlam building and the Stock Exchange have each taken some financial functions to an inconvenient distance from Hollard Street, and each in a different direction.

With decentralization of retailing and employment already occurring, implementation of many of the Driessen recommendations seriously threatens the future of our CBD's. Rather than the Driessen emphasis on controls and restrictions - negative measures designed to reduce the flow of cars into the CBD - an urban transport policy should focus on positive measures to encourage the efficiency and use of public transport to achieve the same end. The presence of an effective public transport system may be the most important factor in ensuring the continuing viability of CBD's. Real Estate Research Corporation (RERC), a highly respected US consulting firm, has just completed an examination of the future of the US real estate market. Their analysis suggests that although most central cities of over 100000 people will lose population during the 1980 s, larger cities with mass transportation will enjoy increasing levels of retail sales and office employment. RERC predicts that 'public transportation, long an American stepchild, will gain both wider acceptance and greater use as energy remains a dominant issue in the 1980s'.

The above examples of deficiencies in the Driessen Commission Report indicate that the Commission's recommendations are not the answer to many aspects of the urban transport problem, and implementation of certain measures may result in more harm than good.

It is important that the Driessen Commission Report not be accepted as official government policy. No one planning document can be expected to hold the key to all the country's transportation planning questions, and certainly not for the long term. Alternatives need to be analyzed and developed to a level of detail comparable to the Driessen view. Without this, a trend of decisions based solely on the Driessen Report - as in JOMET planning - will begin to emerge and the recommendations of the Driessen Commission will become 'official'. An opportunity for deliberate policy-making in the field of urban transport will be lost to passive acceptance. 